\title{
Developing strategic plans for an aligned approach to 2 I st century skills integration
}

March 202I

The Global Education Monitoring (GEM) Centre supports education stakeholders to collect, analyse and use high-quality data to improve learning outcomes. The GEM Centre is a long-term partnership between the Australian Council for Educational Research (ACER) and the Australian Government's Department of Foreign Affairs and Trade (DFAT). 
Developing strategic plans for an aligned approach to $21^{\text {st }}$ century skills integration

Claire Scoular and lan Teo ㄷ 2021

The Australian Council for Educational Research

19 Prospect Hill Road

Camberwell VIC 3124

Phone: (03) 92775555

ABN 19004398145

www.acer.org

ISBN 978-1-74286-626-0

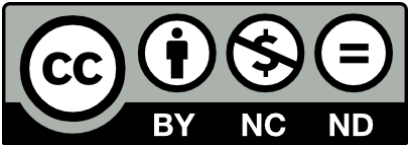

With the exception of any material protected by a trademark, and where

otherwise noted, all material presented in this document is provided under a

Creative Commons Attribution NonCommercial NoDerivatives 4.0 International Licence

\section{Recommended attribution}

The Australian Council for Educational Research must be attributed as the copyright holder of this publication. To request use outside this licence, email: permissions@acer.org

\section{Recommended citation}

Scoular, C. \& Teo, I. (2021). Developing strategic plans for an aligned approach to $21^{\text {st }}$ century skills integration. Australian Council for Educational Research. https://doi.org/10.37517/978-1-74286626-0

\section{Acknowledgements}

This report was funded by the Australian Government's Department of Foreign Affairs and Trade (DFAT) and the Australian Council for Educational Research (ACER), through a partnership known as the Global Education Monitoring Centre (GEM Centre). The course was delivered in collaboration with the Network on Education Quality Monitoring in Asia-Pacific (NEQMAP) and additional funding was provided by GPE. The authors of the report would like to acknowledge the contribution of the NEQMAP secretariat and the valuable input provided by Mark Manns and Phenwilai Chaiyaporn of UNESCO Bangkok. 


\section{Table of Contents}

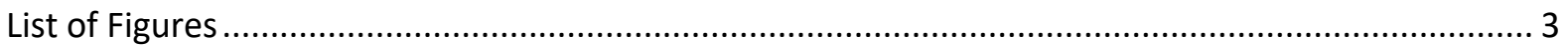

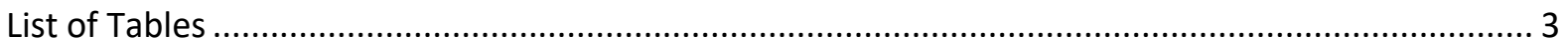

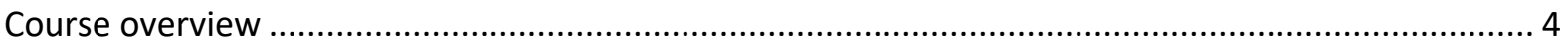

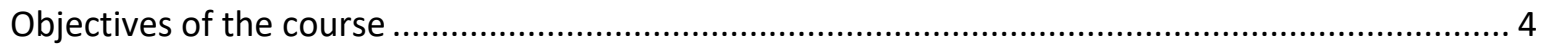

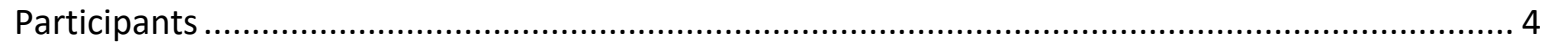

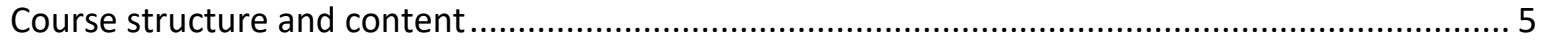

Module 1. Overview of an aligned approach to skills integration and Core Strategy Team.................6 6

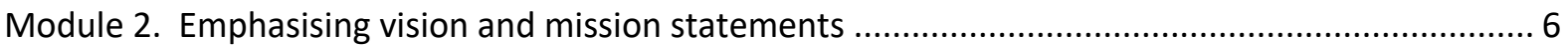

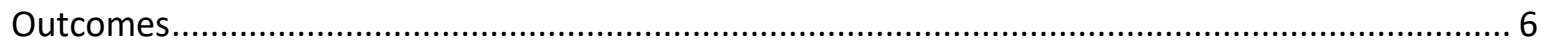

Module 3. Adopting skills frameworks and definitions ............................................................... 8

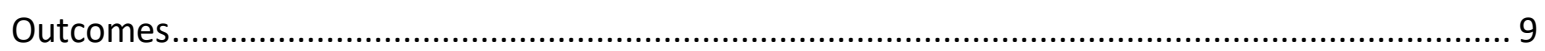

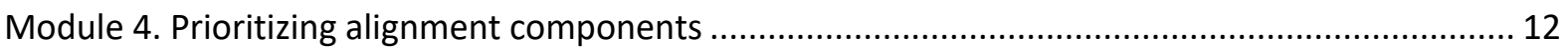

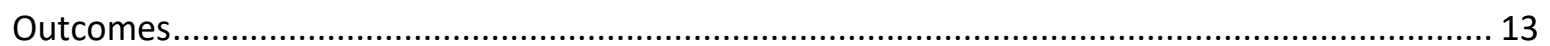

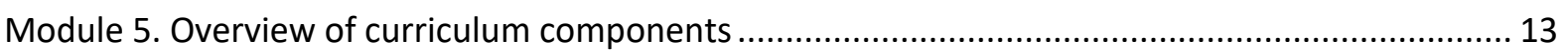

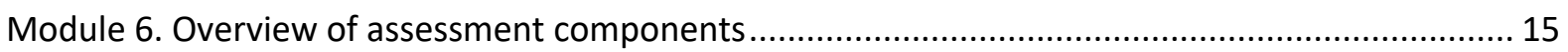

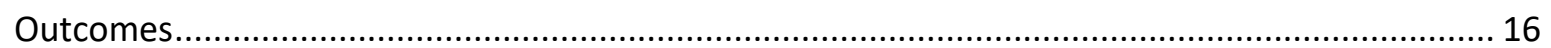

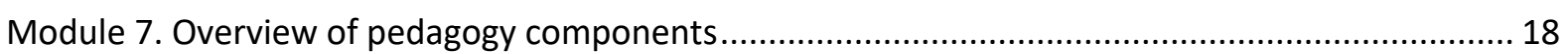

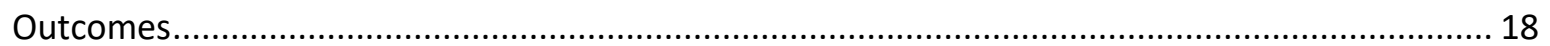

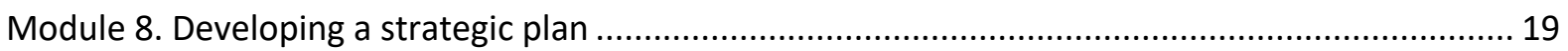

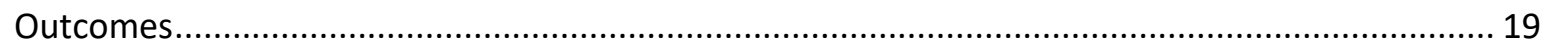

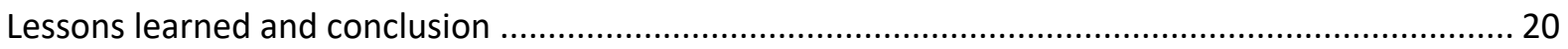

\section{List of Figures}

Figure 1. Aligning 21st century skills assessment, curriculum and pedagogy.................................. 12

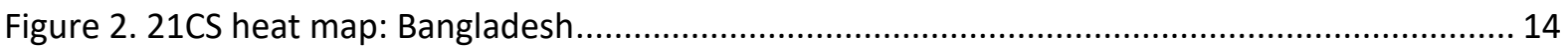

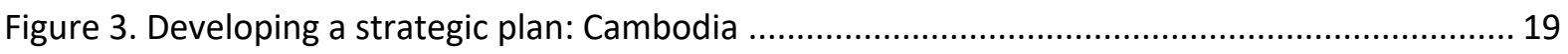

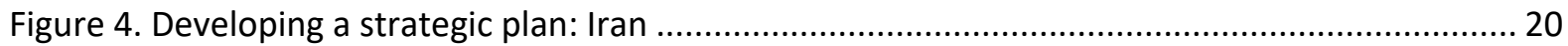

\section{List of Tables}

Table 1. List of participating education systems and associated departments .................................. 5

Table 2. Skill explicitly referenced in vision and mission statements ............................................... 7

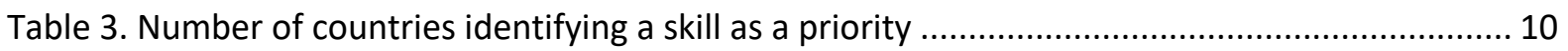

Table 4. Aligning a curriculum model and teacher standards framework: Brunei Darussalam........... 10

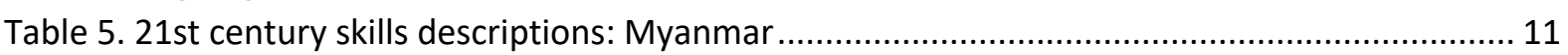

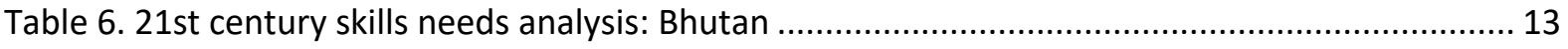

Table 7. 21CS audit of the curriculum: Federated States of Micronesia .......................................... 15 


\section{Course overview}

The integration of 21st Century Skills (21CS) in education systems has been identified as a key area of interest for policymakers. This fully integrated approach requires alignment at a systems level, and should encompass curricular, assessment, and pedagogical (i.e., teaching and learning) components. Many countries are seeking viable options for skills integration in education systems.

The online course described in this report addresses the extent to which 21CS can be sustainably and fully mainstreamed and integrated into education systems. While different countries may have their own frameworks or priorities surrounding 21CS, a consistent approach to integration can still be achieved with a shared understanding from all stakeholders within the system. 21CS are those skills that are considered particularly important to succeed in today's knowledge-based society in which innovation and technology are predominant. Prominent examples include critical thinking, creative thinking, and collaboration, and such skills need to be better understood in order for them to be integrated. There is acknowledgement that traditional approaches to curriculum, assessment, and pedagogy might not be sufficient for monitoring these skills and, as such, innovative methods and technologies need to be employed.

\section{Objectives of the course}

The aim of the course was to support systems to build an aligned and sustainable approach to 21CS integration. This was achieved via overall objectives that focused on supporting countries to develop a strategic plan for 21CS integration, providing resources to aid that plan, and building capacity to implement the plan. The specific learning objectives were to:

- Understand components and steps leading to 21CS alignment;

- Conduct a needs analysis, identifying which steps are currently being met, and which steps need more attention;

- Develop a strategic plan, identifying which steps are to be prioritized and in which order;

- Gain insights from other education systems from reflections on successful developments and lessons learned; and

- Engage in discussion within education systems and with other countries about the emerging area of skills integration, as well as identify future directions.

\section{Participants}

Participants joined from across 16 Asia Pacific countries and from the Education Quality and Assessment Programme for the Pacific Community (EQAP) (Table 1). In an aligned system, educators with expertise in curriculum development, assessment design, and pedagogical strategies are brought together to form a Core Strategy Team that will design the support structures and substance required for a coherent approach. The strategic plan will be driven by this team, and it is necessary that all activities under the strategic plan are discussed and reflected upon at regular meetings. The successful alignment of 21CS integration is contingent upon the Core Strategy Team effectively collaborating and communicating with each other. A prerequisite to join this course was that education system teams comprised of at least one representative from each of the respective assessment, curriculum, and pedagogy divisions. The resulting teams had approximately five representatives and formed a Core Strategy Team. 
Table 1. List of participating education systems and associated departments

\begin{tabular}{|c|c|}
\hline Country & Education system / Associated department \\
\hline Afghanistan & Ministry of Education for Literacy \\
\hline Bangladesh & $\begin{array}{l}\text { National Curriculum and Textbook Board, Directorate of Secondary and Higher } \\
\text { Education, Board of Intermediate and Secondary Education }\end{array}$ \\
\hline Bhutan & $\begin{array}{l}\text { Bhutan Council for School Examinations and Assessment, } \\
\text { Royal Education Council and Assessment }\end{array}$ \\
\hline Brunei Darussalam & $\begin{array}{l}\text { Curriculum Development Department, Department of School, Examination Department, } \\
\text { Department of Educator Management }\end{array}$ \\
\hline Cambodia & Education Quality Assurance Department \\
\hline EQAP & $\begin{array}{l}\text { Curriculum and Assessment Department, Educational Quality and Assessment Program } \\
\text { (EQAP) }\end{array}$ \\
\hline Federated States of Micronesia & Improving the Quality of Basic Education Project (IQBE), Asian Development Bank \\
\hline Fiji & Curriculum Development Unit, Ministry of Education \\
\hline Iran & Organization for Educational Research and Planning \\
\hline Malaysia & Curriculum Development Division \\
\hline Maldives & Ministry of Higher Education \& Quality Assurance MOE \\
\hline Mongolia & Department of Primary and Secondary Education Policy \\
\hline Myanmar & Test \& Measurement Unit, Department of Myanmar Examination, MOE \\
\hline Nepal & National Assessment of Student Achievement, Education Review Office \\
\hline Papua New Guinea & Monitoring and Evaluation, Department of Education \\
\hline Uzbekistan & State inspectorate on Supervision of Quality in Education \\
\hline Vietnam & Centre of Education Quality Evaluation, Ministry of Education and Training \\
\hline
\end{tabular}

\section{Course structure and content}

The course comprised of eight modules that were spread over three weeks, with content hosted online through the Moodle platform. Participants were provided a login to access materials that were designed to be completed in order during the assigned week. Each module consisted of prerecorded video content ( $30-60$ minutes) and team and/or individual activities. Team activities were intended to be completed by Core Strategy Team members collaboratively and led by the assigned Focal Person. The modules were also supported by three live sessions that allowed participants to ask questions and share reflections in real time. The course concluded with a webinar that consisted of presentations that were delivered by one member from each Core Strategy Team who shared their team's strategic plan and reflections from this course. 
This first module presented the four steps to develop a strategic plan, and therefore served as an important basis for the remaining modules. A strategic plan is required to put policy into practice and drive a 21CS integration agenda. Teaching and enhancement of 21CS in the classrooms of formal education systems has had a relatively short life. With increasing awareness of the need for students today to develop their 21CS to greater proficiency, education systems have only recently started to introduce these skills explicitly into their learning goals.

The course outlined four proposed steps for developing a strategic plan for 21CS alignment, with the modules working through these in sequence:

Step 1. Establishing a Core Strategy Team

Step 2. Emphasizing vision and mission statements

Step 3. Adopting skill frameworks and definitions

Step 4. Prioritizing alignment components:

a. Curriculum | b. Assessment | c. Pedagogy

\section{Module 2. Emphasising vision and mission statements}

In Module 2, the considerations for emphasizing 21CS within an education system were discussed. A vision and mission statement with reference to a 21CS agenda is the first step in the strategic plan. This firmly places 21CS as a priority, identifies which skills are of most importance nationally, and clarifies how these should be communicated and widely disseminated to stakeholders.

Participants were asked, in their Core Strategy Team, to identify and draft their own vision and mission statement in relation to $21 \mathrm{CS}$, and to reflect on how these are currently emphasized and disseminated. Participants were asked to reflect and discuss how their own statement compared with those presented by other education systems. They were also asked to reflect on how their dissemination compared with the other statements selected and what can be done to strengthen the dissemination of their own statement.

\section{Outcomes}

There was variety in the terminology used. Although this course adopted the term 21CS, participants were encouraged to use the term already adopted by their country. Other than $21 \mathrm{CS}$, the terms adopted by other countries included: holistic skills/education, life skills, core competencies, $21^{\text {st }}$ century competencies, transversal competencies, and soft skills. In many cases these terms were inclusive of both 21CS and characteristics and dispositions that are of value to the country, therefore, some of these terms are not necessarily synonymous with 21CS but are inclusive of a broader set of attributes.

Existing statements. The majority of countries already had a vision and mission statement that they could reflect on. Most vision statements identified the overall characteristics that they wanted students to emerge from the education system with. For example:

"...to foster intellectual, innovative, confident and informed citizens..."

"To develop competent and competitive citizens for building socialism-oriented, social justice-based prosperous nation." 
"...strive to have wise, productive citizens who are capable of regulating their emotions, thoughts and actions and also promote the health of themselves and the world beyond."

Most mission statements identified how the education system would achieve the vision statement. For example:

"...a system that fosters excellence and empowers responsible citizens to be caring and successful lifelong learners"

"...empower them to strive in the 21st century by integrating the skills into curriculum, assessment and teacher training policies."

"...deliver a quality, sustainable basic education system which provides all students with basic skills, independence, creative and critical thinking skills; focuses personal development; provides for the employment needs of the state."

Consistencies in skills. Approximately half of the vision and mission statements explicitly identified specific skills. Of the remaining countries, most had a clear agenda in relation to specific skills of interest, but these were not necessarily presented explicitly in the vision and mission statements. Those skills that were explicitly stated in vision and mission statements can be seen in Table 2 .

Table 2. Skill explicitly referenced in vision and mission statements

\begin{tabular}{ll} 
Skill & $\begin{array}{l}\text { Number of countries } \\
\text { presenting it explicitly in their } \\
\text { vision and mission statement }\end{array}$ \\
\hline Creativity/ Creative thinking & 9 \\
Critical thinking & 7 \\
Literacy & 5 \\
Problem solving & 5 \\
Collaboration & 5 \\
Numeracy & 4 \\
Communication & 4 \\
ICT & 3 \\
Self-regulation & 3 \\
Cooperation & 3
\end{tabular}

National priorities. Despite there being a lot of commonalities regarding the desired characteristics and skills of students, across education systems, there was an emphasis of national values and cultural pride. This suggests that while there is a general sense of how we envision our students' education across the Asia-Pacific, importance is still placed on highlighting the cultures and traditions within a country and how they might be prioritized. For example:

"...upholds the nation's unique cultural and spiritual heritage and values..." 
"Citizens who are able to adapt quickly to a changing environment for continuous participation in a dynamic and sustainable economy, in order to sustain the nation's economic development, social and political stability and maintaining competitive advantages."

Dissemination. Generally, the dissemination methods were consistent between education systems with most identifying websites, curriculum resources, training sessions, and seminars, as the primary methods for dissemination. Many countries also identified that they could also adopt one of the methods from another education system that they had not already utilised. For example, some education systems utilised social media more, one education system had a parent engagement form, and another education system conducted a Ministry of Education roadshow.

\section{Module 3. Adopting skills frameworks and definitions}

This module focused on adopting skills frameworks that include detailed definitions of the skills. While frameworks and umbrella terms for skills are common place, these often lack detail in respect to what the skills actually look like from evidence-based research. This lack of detailed description about the skills leaves teachers uncertain of what they look like, how they develop, and how they should be implemented. With different perspectives on terminology and little concrete evidence, educators are understandably uncertain about which perspective to adopt, or how to move forward in their practice. Additionally, the need to accommodate sociocultural perspectives and practices, as highlighted in Module 2, presents another dimension of complexity that educators and policymakers must negotiate. Teachers are expected to teach and assess these skills without any formal training to do so, and without any evidence presented as to how they are demonstrated in the classroom. Accordingly, detailed definitions provide a platform from which to teach and assess using a common terminology.

ACER provided course participants with detailed definitions and evidence-based frameworks for three 21CS. These skills were focused on in more detail in this module and consisted of:

- Collaboration: Skill development framework ${ }^{1}$.

- Creative thinking: Skill development framework ${ }^{2}$.

- Critical thinking: Skill development framework ${ }^{3}$.

The approach taken in these frameworks was to break down the skills to ensure better comprehension of their nature and structure. Each skill is structured into strands and aspects with associated demonstrable student behaviours. In this conceptualization, teachers are able to make links between the student behaviours they observe in their classroom and how these are associated with a particular skill. Assessment tasks can also be constructed with specific reference to the aspects. Similarly, the aspects can be used to audit the curriculum and identify teaching strategies.

Participants were asked to reflect on their own definition of each skill and compare to that presented by ACER. Participants were also asked to reflect on their current approach to adopting or identifying skills frameworks. They were asked to identify the specific skills that were of priority to

\footnotetext{
${ }^{1}$ Scoular, C., Duckworth, D., Heard, J., \& Ramalingam, D. (2020). Collaboration: Skill Development Framework. Australian Council for Educational Research. https://research.acer.edu.au/ar_misc/42

2 Ramalingam, D., Anderson, P., Duckworth, D., Scoular, C., \& Heard, J. (2020). Creative Thinking: Skill Development Framework. Australian Council for Educational Research. https://research.acer.edu.au/ar_misc/40

3 Heard, J., Scoular, C., Duckworth, D., Ramalingam, D., \& Teo, I. (2020). Critical Thinking: Skill Development Framework. Australian Council for Educational Research. https://research.acer.edu.au/ar_misc/41
} 
them and reflect on which skills frameworks and definitions documentation they had developed or adopted in relation to these skills.

\section{Outcomes}

Extension of understanding. Most participants reported that the level of detail in the skill development frameworks extended their understanding and their own definition of the skills. For example:

Critical thinking

"ACER's definition further extended mine by emphasizing reasoning as a different strand/aspect that is within critical thinking."

"ACER's critical thinking definition was appropriate for the purpose of insightful knowledge, understanding hypothesis and belief which was missing in my definition. My understanding of it is only to think reasonably and make consistent connection between ideas. So, in other words, ACER is more detailed with deeper meaning."

"ACER's definition had appropriate standards that was represented by truth, responsibilities and logic. This was one part I never thought of while defining critical thinking."

Creative thinking

"ACER's definition includes unusual ways to make unconventional connections to outline novel possibilities which I never thought about it before."

"I only thought that this skill focuses on the first strand only: Generation of Ideas. But now I learned, and it makes senses, that any ideas can be experiment or tried in order to come up with the right answer (the quality)."

"Manipulating ideas in unusual ways and make unconventional connections was new and not included in my definition."

Collaboration

"I will extend my definition with the theme of contribution in the group, division of the task and discourse. And I make my new understanding as contribution, task division and get a result or complete the task."

"It challenged my definition because effective collaboration involves a division of labour and it resolves differences."

"I am also challenged to realize the difference between cooperation and collaboration. Cooperation depends upon a balance of action with learners working on parallel tasks and eventually bringing both parts together as one while the latter requires learners working together on the same task where the division of labour is intertwined and therefore requires interdependent tasks to solve a problem."

Prioritising of skills. The skills prioritised by education systems varied but there was consistency across a number of the skills. Those skills prioritized by education systems can be viewed in Table 3 . 
Table 3. Number of countries identifying a skill as a priority

\begin{tabular}{lr} 
Skill & $\begin{array}{l}\text { Number of countries identifying } \\
\text { that skill as a priority }\end{array}$ \\
\hline Collaboration & 14 \\
Communication & 14 \\
Creativity/ Creative thinking & 11 \\
Critical thinking & 11 \\
Problem solving & 10 \\
ICT/ Digital literacy & 9 \\
Self-regulation & 9 \\
Literacy & 6 \\
Information literacy & 5 \\
Numeracy & 4 \\
Decision making & 3 \\
Responsibility & 3 \\
Empathy & 2 \\
Cooperation & 2 \\
\hline
\end{tabular}

Lack of detailed documentation. Approximately two thirds of the countries identified that they did not have detailed definitions documentation or frameworks for the skills they are prioritizing. Support to develop additional framework documentation was a main request of participants at the end of the course. Three countries - Cambodia, Nepal and Mongolia - were participants in the Optimizing Assessment for All project in 2018 and received technical support from the Brookings Institution and ACER, and were funded by GPE and NEQMAP, to develop skills frameworks for some of their prioritized skills ${ }^{4}$. They were able to reflect on these frameworks during the course and, where similar skills were outlined, review and map these in comparison to the ACER skill development frameworks.

A couple of education systems had reached the stage of explicitly identifying the skills in the documentation. For example, the Brunei Darussalam system identified a curriculum model framework for five skills, and aligned these to a teacher standards framework (Table 4).

Table 4. Aligning a curriculum model and teacher standards framework: Brunei Darussalam

\begin{tabular}{lll} 
Skills & SPN 21 Curriculum Model framework & Brunei Teacher Standard framework \\
\hline Collaboration & B5 - Collective decisions and actions. & $\begin{array}{l}\text { B7 - Majority students collaborate by having } \\
\text { shared responsibility, making rational decisions } \\
\text { effectively with some beyond their expected level. } \\
\text { They negotiate in producing quality work. }\end{array}$ \\
& $\begin{array}{l}\text { C1.3d Teachers intertwine discussion in pairs, } \\
\text { small groups and the whole class seamlessly. They } \\
\text { build on what they hear during paired and small }\end{array}$
\end{tabular}

\footnotetext{
${ }^{4}$ Care, E., Vista, A. \& Kim, H. (2020). Optimizing assessment for all. Focus on Asia. Brookings Institute. https://www.brookings.edu/wp-content/uploads/2020/03/OAA-Focus-on-Asia-FINAL.pdf
} 


\begin{tabular}{|c|c|c|}
\hline & & $\begin{array}{l}\text { group discussion to facilitate productive whole } \\
\text { class discussion. }\end{array}$ \\
\hline Communication & $\begin{array}{l}\text { B2 Communication skills - development of } \\
\text { communication that includes listening, speaking, } \\
\text { reading and writing. }\end{array}$ & $\begin{array}{l}\text { B1 Majority students demonstrate strong } \\
\text { communication skills, with some exceeding } \\
\text { learning expectations, by articulating thoughts } \\
\text { and ideas clearly and effectively through speaking } \\
\text { and/or writing. }\end{array}$ \\
\hline \multirow[t]{2}{*}{$\begin{array}{l}\text { Creative and } \\
\text { Critical }\end{array}$} & $\begin{array}{l}\text { B5 Thinking and Problem Solving Skills - involve } \\
\text { acquisition of knowledge, dispositions, and cognitive } \\
\text { and meta-cognitive operations. The problem solving } \\
\text { skills are linked to the process of thinking, hypothesis } \\
\text { formation, investigating, analysing and decision } \\
\text { making. These tools are needed in a society }\end{array}$ & $\begin{array}{l}\text { A4 - Majority students are highly competent, with } \\
\text { some beyond their level range, at analysing } \\
\text { (compare, contrast, differentiate, distinguish, etc.) } \\
\text { and evaluating (assess, measure, justify, review, } \\
\text { etc.). }\end{array}$ \\
\hline & $\begin{array}{l}\text { characterised by rapid changes which involve many } \\
\text { alternative choices, individual and collective decisions } \\
\text { and actions. }\end{array}$ & $\begin{array}{l}\text { C1.3c - Teachers respond to students' answers } \\
\text { reflectively. They choose their responses based on } \\
\text { students' answers in order to identify and address } \\
\text { misconceptions, challenge thinking and deepen } \\
\text { understanding. }\end{array}$ \\
\hline ICT skill & $\begin{array}{l}\text { B4 - Information Communication Technology (ICT) } \\
\text { Skills These skills have become an integral part of the } \\
\text { 21st Century education. They should be mastered by } \\
\text { learners in line with the rapid technological } \\
\text { advancements and globalisation. }\end{array}$ & $\begin{array}{l}\text { B6 - Majority students are highly skilled at using } \\
\text { digital technology, communication tools or } \\
\text { networks appropriately to access, manage, } \\
\text { integrate and create information, with some } \\
\text { exceeding the learning expectations. }\end{array}$ \\
\hline
\end{tabular}

Adoption of frameworks. Generally, participants felt they would be able to use the ACER skill development frameworks for critical thinking, creative thinking and collaboration in their contexts although some variances in terminology may be applicable.

Need for understanding growth. Few education systems have reached the stage of identifying levels of progression within the skills. However, the Bangladesh system has described five levels for each of their skills - preparatory, developing, activating, achieving, and upgrading. The Myanmar system has also begun to delineate descriptions of skills in relation to grade level expectations as per Table 5.

Table 5. 21st century skills descriptions: Myanmar

\begin{tabular}{|c|c|c|}
\hline Skills & Grade level & Description \\
\hline Collaboration & $\begin{array}{l}\text { Grade } 6 \\
\text { Grade } 10\end{array}$ & $\begin{array}{l}\text { Encourage students to work in groups, share ideas, and find solutions together. } \\
\text { Work in groups, sharing their ideas with friends and find solution to problems } \\
\text { together. }\end{array}$ \\
\hline Communication & $\begin{array}{l}\text { Grade } 6 \\
\text { Grade } 10\end{array}$ & $\begin{array}{l}\text { Verbal and non-verbal communication: reading, writing, speaking and listening. } \\
\text { Express their thoughts and ideas effectively using oral, written and nonverbal } \\
\text { communication and listen effectively to work out meaning. }\end{array}$ \\
\hline $\begin{array}{l}\text { Critical Thinking } \\
\text { and Problem Solving }\end{array}$ & $\begin{array}{l}\text { Grade } 6 \\
\text { Grade } 10\end{array}$ & $\begin{array}{l}\text { Let students find solutions to problems and correct errors. } \\
\text { Reason, analyze, evaluate, solve problems, make decisions, look for errors and } \\
\text { correct them. }\end{array}$ \\
\hline Citizenship & $\begin{array}{l}\text { Grade } 6 \\
\text { Grade } 10\end{array}$ & $\begin{array}{l}\text { Active participation in the school community and development of fairness and } \\
\text { conflict resolution skills. } \\
\text { Engage in school community and develop fairness and conflict resolution skills. }\end{array}$ \\
\hline
\end{tabular}




\section{Module 4. Prioritizing alignment components}

In Module 4, the concept of aligning assessment, curriculum, and pedagogy, and the associated ten alignment steps itemized in the Figure 1 boxes below, were discussed. The 10 steps are not intended to be prescriptive or linear in nature. Rather, once familiar with the details of each step, they can be used to guide two activities: 1) To conduct a needs analysis, identifying which alignment steps are currently being met, and which need more attention (Module 4 outcome) and 2) To develop a strategic plan, identifying which alignment steps are to be prioritized and in what order (course outcome). The alignment steps can provide a benchmark from which systems can review their current status of 21CS integration, as well as provide a way to identify priorities for integration and target those systematically.

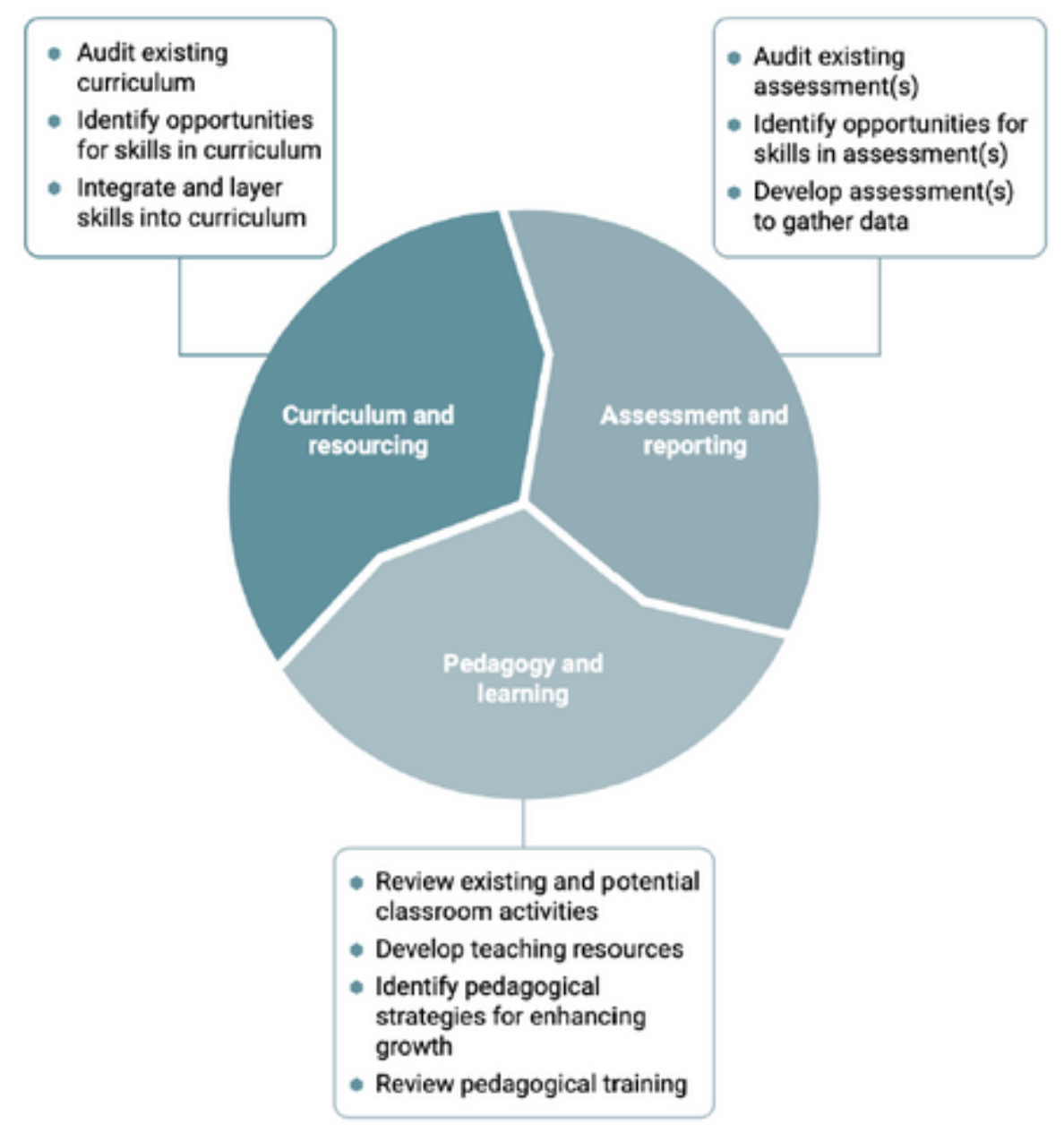

Figure 1. Aligning 21st century skills assessment, curriculum and pedagogy

An aligned approach to skills integration requires considerations of assessment, curriculum, and pedagogy. The curriculum component of skills integration can ensure that there are appropriate learning goals to empower learners of all ages to assume active roles-both locally and globallyand make informed decisions for building a more sustainable future through peaceful, tolerant, inclusive, and secure societies. The assessment component can transform learning targets towards the goals both within the classroom, and at the country level. The pedagogical component can build the capacity of educators and expand the scope of resources available. 
As a team, participants were asked to review each of the 10 alignment steps, place the steps in order of priority, identify the status of each step (Completed, Underway, or Not yet started), and identify the key issues in implementing that step.

\section{Outcomes}

Prioritization of steps. While the order of steps varied to suit the individual needs of the education systems, there were two steps that were consistently prioritized by the majority of education systems - auditing curriculum and auditing assessments. This suggests there is benefit in reviewing the presence of skills in existing documentation before planning how to further integrate.

Status of steps. The status of the steps and degree 21CS integration varied across education systems; with the upper end of integration being exemplified by the education system in Afghanistan currently undergoing curriculum reform to embed 21CS. An example of the output from the needs analysis (Bhutan) is presented in Table 6.

Table 6. 21st century skills needs analysis: Bhutan

\begin{tabular}{lll} 
Step & Components & Status \\
\hline 1 & Audit existing Curriculum & $\begin{array}{l}\text { Not yet } \\
\text { started }\end{array}$ \\
2 & Audit existing assessment & $\begin{array}{l}\text { Not ye } \\
\text { started }\end{array}$ \\
3 & $\begin{array}{l}\text { Review existing and potential } \\
\text { classroom activities }\end{array}$ & Started
\end{tabular}

$4 \quad$ Identify pedagogical strategies Started for enhancing activities

$5 \quad$ Integrate and layers skills into Started curriculum

$6 \quad$ Develop assessment(s)

Started

7 Identify opportunities for skills Started in curriculum

$8 \quad$ Identify opportunities for skills Started in assessment(s)

9 Develop teaching resources Started

10 Review pedagogical training Started
Comments

Curriculum audit would provide us clear picture of its quality, implementation and review of the curriculum

Assessment audit be instrumental in informing us the purpose served by the present system of assessment and according revamp the assessment components and methods to cater to need of society. The curriculum material presented must be well synchronized with classroom activities and to review the existing activity as many activities may be outdated with emerging of new technologies and trends. (Al)

How flowery and beautiful the curriculum and assessment material may be, they would of less use or may not be able to bring the intended outcome if pedagogy goes wrong

21st century has demanded the skilled and competent people in any setting they work. These skills mentioned in the course must be learnt by embedding in curriculum assessment and pedagogy

Assessment would help to diagnosis the output of the curriculum and amend the curriculum and pedagogy accordingly to the data generated through assessment.

The good curriculum must have well-structured content, skills and values clearly reflected to be achieved at that grade. The curriculum in Bhutan is designed based on more emphasis on skills and values in line with Philosophy of GNH

The recent reform in curriculum is aligned to assess knowledge, skills and values equally to bring authentic and competency-based assessment. The assessment emphases on process than end product to develop the skills

Teaching resources are developed in soft and hard copies for textual information, models (3D model, illustration, working model), recorded videos, readymade resources purchased and distribute to the schools.

The comprehensive training is provided to all the teachers and professionals on the event of any new reforms in curriculum, assessment and management.

\section{Module 5. Overview of curriculum components}

This module focused on the alignment steps contained in the curriculum component of the alignment model. The process of a skills curriculum audit was discussed, of which the end goal would 
be to develop a 'heat map' highlighting the presence of 21CS in curriculum documentation. The intention of the course was not to necessarily conduct a curriculum audit, but to envision the optimal embedding of skills for each country. Each education system may not want to embed every skill into every learning area, or embed the skills equally across learning areas. Therefore, in this course, the heat map was intended to outline where systems want to embed skills (and which skills) into key learning areas and when across the schooling years. The 'heat map' allowed systems to identify where 21CS focus should be in the curriculum, and to identify where additional skills integration might be most useful.

The teams were provided with a heat map template and asked to envision which skills would optimally be embedded into which learning areas. Participants were asked to enter their learning areas into the table along the top row, and the skills they identified in Module 2 as a priority in the first column. They also had the choice of narrowing their reflections to a particular grade(s) of students. Participants were asked to place the appropriate colour in each corresponding box (red=little to no coverage, yellow=some coverage, green=lots of coverage).

\section{Outcomes}

Identification of optimal coverage. Each education system presented their optimal heat maps. One example from the Bangladesh team is presented below where red indicated 'little to no coverage' is intended, yellow where 'some coverage' is intended, and green where 'lots of coverage' is intended.

\begin{tabular}{|l|l|l|l|l|l|l|l|l|l|}
\hline & $\begin{array}{l}\text { Language and } \\
\text { Communications }\end{array}$ & $\begin{array}{l}\text { Mathematics } \\
\text { \& Reasoning }\end{array}$ & $\begin{array}{l}\text { Science } \\
\text { and } \\
\text { Technology }\end{array}$ & $\begin{array}{l}\text { Information \& } \\
\text { Communication } \\
\text { Technology }\end{array}$ & $\begin{array}{l}\text { Society \& } \\
\text { Global } \\
\text { Citizenship }\end{array}$ & $\begin{array}{l}\text { Life and } \\
\text { Life \& } \\
\text { Livelihood }\end{array}$ & $\begin{array}{l}\text { Values } \\
\text { \& } \\
\text { Morality }\end{array}$ & $\begin{array}{l}\text { Physical- } \\
\text { Mental } \\
\text { Health \& } \\
\text { Protection }\end{array}$ & $\begin{array}{l}\text { Arts \& } \\
\text { Culture }\end{array}$ \\
\hline Problem solving skills & & & & & & & & & \\
\hline Critical thinking skills & & & & & & & & & \\
\hline Creative thinking skills & & & & & & & & & \\
\hline Literacy \& Numeracy & & & & & & & & & \\
\hline Digital Literacy & & & & & & & & & \\
\hline Decision making skills & & & & & & & & & \\
\hline Communication skills & & & & & & & & & \\
\hline Self-management skills & & & & & & & & & \\
\hline Collaboration skills & & & & & & & & & \\
\hline Global citizenship skills & & & & & & & & & \\
\hline
\end{tabular}

Figure 2. 21CS heat map: Bangladesh

Comparison of optimal embedding to existing curriculum. As noted earlier, this exercise was not intended to reflect the existing curriculum (future curriculum audits could be conducted to complete this work), but aimed to build a picture of what participants wanted their curriculum to look like, and where their priorities lay in terms of embedding the skills. However, some education systems took this opportunity to reflect on the difference between their heat map and their existing curriculum. About half of the education systems identified that the skills are not yet presented explicitly in their curriculum documentation and that further work to embed skills more intentionally in the curriculum is intended in future plans.

Review of existing curriculum. A couple of education systems did take the opportunity during this activity to conduct an audit of their existing curriculum. For example, the Federated States of 
Micronesia (FSM) team reviewed documents at both the national and state levels for any inclusion of 21CS. FSM has national curriculum standards and benchmarks in the subjects of language, mathematics and science from grade 3 through to high school and college preparatory programs. The audit conducted for language Arts is presented in Table 7.

Table 7. 21CS audit of the curriculum: Federated States of Micronesia

FSM Benchmarks

Build comprehension of texts.

Respond to oral and visual communications.

Ask and answer questions at different cognitive levels.

Read a variety of level appropriate texts for a variety of purposes.

Discuss the moral of a story or piece of literature and compare it to their own cultural values.

Listen and critically respond to oral and visual communication.

Interact in conversations and discussions of medium complexity.

Apply a variety of strategies to build comprehension.

Make presentations on topics of medium complexity.

Listen, view and respond to oral and visual communication.

\section{Activities}

Students will be able to ask questions, predict, identify main ideas and supporting details, analyze, summarize and draw logical conclusions.

Students will be able to engage in conversations, discussions and debates and demonstrate understanding of plays, presentations and illustrated talks by commenting and discussing and asking and answering questions.

Students will be able to compose and answer questions that relate to Bloom's cognitive levels: 1.Knowledge; 2. Comprehension; 3. Application; 4. Analysis; 5. Synthesis; 6. Evaluation.

Students will be able to read narratives, reports, descriptions, maps, charts and graphs in order to find information, follow directions, critically analyze or for pleasure.

Students will be able to state their point of view and participate in discussions.

Students will be able to draw conclusions and comment critically on speeches, reports and dramas.

21CS

Critical Thinking:

Analyze and Draw Logical Conclusions

Collaboration

Critical Thinking

Critical Thinking

Students will be able to participate in paired and group discussions.

Students will be able to activate prior knowledge, predict, visualize and analyze text.

Students will be able to express opinions and discuss the probability of future events.

Students will be able to summarize, analyze, interpret, Creative Thinking evaluate and criticize.

\section{Module 6. Overview of assessment components}

This module presented different types of assessments that are particularly amenable to measuring 21CS skills. Participants were guided through examples, rubrics, and learning progressions relating to some $21 \mathrm{CS}$. They were also encouraged to try responding to some critical and creative thinking assessment examples themselves and, subsequently, use the rubrics to score their team members' responses. Considerations for implementing different types of assessment were presented. This module intended to provide participants with a greater understanding of the skills as well as multiple approaches for measuring them. Optional content was also provided that compared rubrics to progressions and discussed the concept of evaluating and monitoring growth in the skills. Participants were asked to reflect and discuss the types of assessment they currently use and how they would like to measure the skills in the future. 


\section{Outcomes}

Existing assessments. Some countries are more focused on formative classroom-based assessments. For example:

"Assessment of students in primary education concentrates on formative assessment, which heavily stands on authentic assessment forms such as portfolios, observation, and performance assessment."

"Formative assessment which focusing mainly on individual student performance (e.g. class works, quizzes, tests, homework, etc.), portfolio, observation, and interviews. Criterion Reference Tests were also administered to certain grade levels to measure their mastery in tested skills-including 21CS."

"Teachers use observation methods to assess collaboration and communication skills of students by observing directly or recording observations, including behaviour in group work in preparation for practical or performance activities. Teacher use oral questioning method to assess the critical thinking and creative skill of students in formative assessment."

"...formative assessment is currently being used in assessing the skills. The assessments are marked against a rubric and different methods of assessment such as observation, discussion and questioning and student productions are undertaken."

Some countries are also embedding measures of 21CS into their existing assessments of key learning areas. For example:

"Standardized Assessment like the NMCT ELA and Math also contained some 21CS where students' mastery is measured against the tested benchmarks."

"In summative assessments (paper and pencil tests), open-ended questions are used to assess students 21Cs skills. In Art and music, students' work qualities (assignment products) are used to assess their creative and collaborative skill."

Focus on classroom formative and authentic assessment. The majority of countries indicated that they were interested in developing classroom assessments that were formative, continuous, and authentic. For example:

"... authentic assessment including but not limited to; assessments that drive the curriculum, performing a task related to real-life, constructing/applying, student-structured, and the assessments that develop higher-order skills."

"Authentic assessment that is realistic, replicates or simulates the real-world contexts and assesses the student's ability to efficiently and effectively use a repertoire of knowledge and skills to negotiate a complex task."

"We would like to have the Authentic Assessment. We would like to use Authentic Assessment But the big challenge is the teacher orientation of the new approach. Normally, teachers use the traditional method."

Data required. Countries value multiple pieces of evidence to establish student ability with prioritized skills; with both quantitative and qualitative data identified as valuable. For example: 
"The authentic assessments should generate both quantitative and qualitative data to measure the progress and achievements of students in 21CS and determine the gaps in students learning."

"...could vary from observations, recording narrations, reports from work groups, student worksheets, teacher self-assessment report and interviews with learners."

"The data will have enough generalizability and credible quality of assessment evidence to support the claims, uses and decisions about introduction of a modern, effective and more balanced system of education sector reforms."

Data usage. Most education systems reflected on the alignment of assessment, curriculum and pedagogy when it came to using assessment data. For example:

"The data will be used to revise curriculum and teacher education policies and frameworks."

"The data can support policy making and help with better implementation."

"Provide the basis for future teaching plans"

"Data can be used for revamping assessment method and support learners to learn better with incorporation of improved pedagogy."

Other countries are also considering using the data to evaluate the outputs of the education system. For example:

"...measure a couple of these competencies and consider them as outputs of the educational system. Again, in new national assessment framework, these kinds of skills would measure in grade 12."

"...they are applied in order of accountability and quality assurance of educational systems."

"Provide a basis for evaluating program effectiveness."

"Evidence based information will be provided to the stakeholders for performance analysis, reporting and improvement strategies, accountability and quality assurance of the school."

Some countries would also like to use the data to review and develop teacher training. For example:

"Teacher's use of 21CS, on how often and whether they employ open-ended questions in their lessons."

"Inform teachers of areas where additional support is needed."

"Professional development programs in the techniques for effective assessment will be provided for current and future teachers, school leaders and education officers. Based on evidence-based data, we will support and sustain the introduction of a modern, effective and more balanced system that assesses student learning progress against national standards, 
contribute to broader education sector reforms including improving the quality of the curriculum, teacher education and assessment."

Several countries also reflected deeply on the progressive nature of their prioritized skills and how these might be evaluated and monitored. For example:

"The data aims to show the present status of each student on these skills as well as the progress they have shown."

"...what individual students and groups of students have learned and the next steps to achieve the 21CS-embedded learning outcomes"

"The data from the assessment will be analysed to track learning progress of students."

"The rubrics and data collection need to be modified in a manner that the data gathered reflects the performance and progress of students in the 21st century skills."

\section{Module 7. Overview of pedagogy components}

This module focused on the skills and training that educators need to teach and assess 21CS skills. Participants were guided through the adaptation of a classroom observation tool that could be used to evaluate current practices in the classroom and target future pedagogical training. They were also guided through examples of teaching strategies for growth of a set of 21CS, as well how to integrate such strategies into existing lesson plans and teaching resources.

Participants were asked to discuss what existing training teachers received on 21CS and what are the intended learning outcomes. They were also asked to reflect on the biggest limitation to teacher training currently and how this could be addressed.

\section{Outcomes}

Existing training. In the majority of participating education systems, teacher training does not explicitly include 21CS. Where it is included this often involves a summary of the vision and mission statements but lacks a depth required to effectively teach and assess the skills. Most training around 21CS appears to take place during pre-service training with a gap identified in most countries during in-service teacher education.

Limitations. There were several limitations that were common among the majority of participating education systems:

- A lack of pedagogical guidance for teachers including evidence-based teaching strategies;

- A large number of students in the classroom leading to more classroom management and less individualised learning;

- A curriculum with many different priorities and a large amount of content which often places too many demands on both teachers and students;

- A lack of time during class to include the skills as well as the content topic;

- A lack of awareness from parents and students regarding the skills and their integration into the education system;

- Lack of access to evidence-based training around 21CS; and

- A lack of connection between prioritizing 21CS in policy documentation and the prioritization of these skills in the classroom. 


\section{Module 8. Developing a strategic plan}

Participants were requested to bring together outputs from across modules, as well as the feedback and other reflections provided from course facilitators and participants. They were guided to create a 3-minute presentation that summarised their strategic plan, including the steps to be prioritised, the order of steps, and the considerations for review. The strategic plans were presented during a live webinar.

\section{Outcomes}

Three examples of the Core Strategy Teams resulting strategic plans are presented below from Cambodia (Figure 3), Iran (Figure 4), and Malaysia (Figure 5).

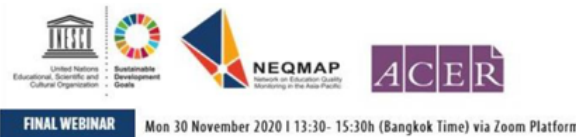

NEQMAP-ACER Online Learning Course: $21^{\text {st }}$ Century Skills Integration:

An Introduction to Alignment Analysis and Strategic Planning

\section{Prioritizing Alignment Components}

a Curriculum Framework (MoEYS, 2015)

- Literacy and Numeracy

- Critical Thinking(Analysis and Creativity)

a Teacher Training Framework Reforms (Underway)

- Student-Learning-Center

- Concept-Base-Learning

- Problem Solving(Applying Knowledge and Skills)

- Collaboration(Communication and Teamwork)

- Constructive-Learning

- Project-Base-Learning

- Inquiry-Base-Learning

- Personal, Family and Society Development

- Basic Local Life skills

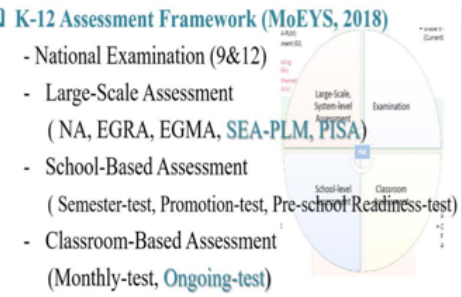

Challenges:

- Lack of $21 \mathrm{CS}$ the detail definitions in curriculum

- The guideline of 21CS implementation has not been

\section{Next Steps}

$>$ Scale up OAA project as base-line of 21CS integration

$>$ Develop the detail guideline of $2 \mathrm{CS}$ implementation

$>$ Develop the teaching guides on how to align 21CS with Concept-BasedLearning (CBL)

21CS assessment tools have not been harmonized

$>$ Develop item bank of $21 \mathrm{CS}$ for providing to teacher as sample item of with the exciting assessment tools

- The limitation of teachers 'capacity to intergrade $21 \mathrm{CS}$ as crossing subjects

- Time constraint for teaching and assessing $12 \mathrm{CS}$ at classroom level summative assessment

$>$ Identify existing items of national assessment to link with $21 \mathrm{CS}$, especially focusing on critical thinking and problem solving.

$>$ Technical discuss on Adopted Strategic Plan

Figure 3. Developing a strategic plan: Cambodia 

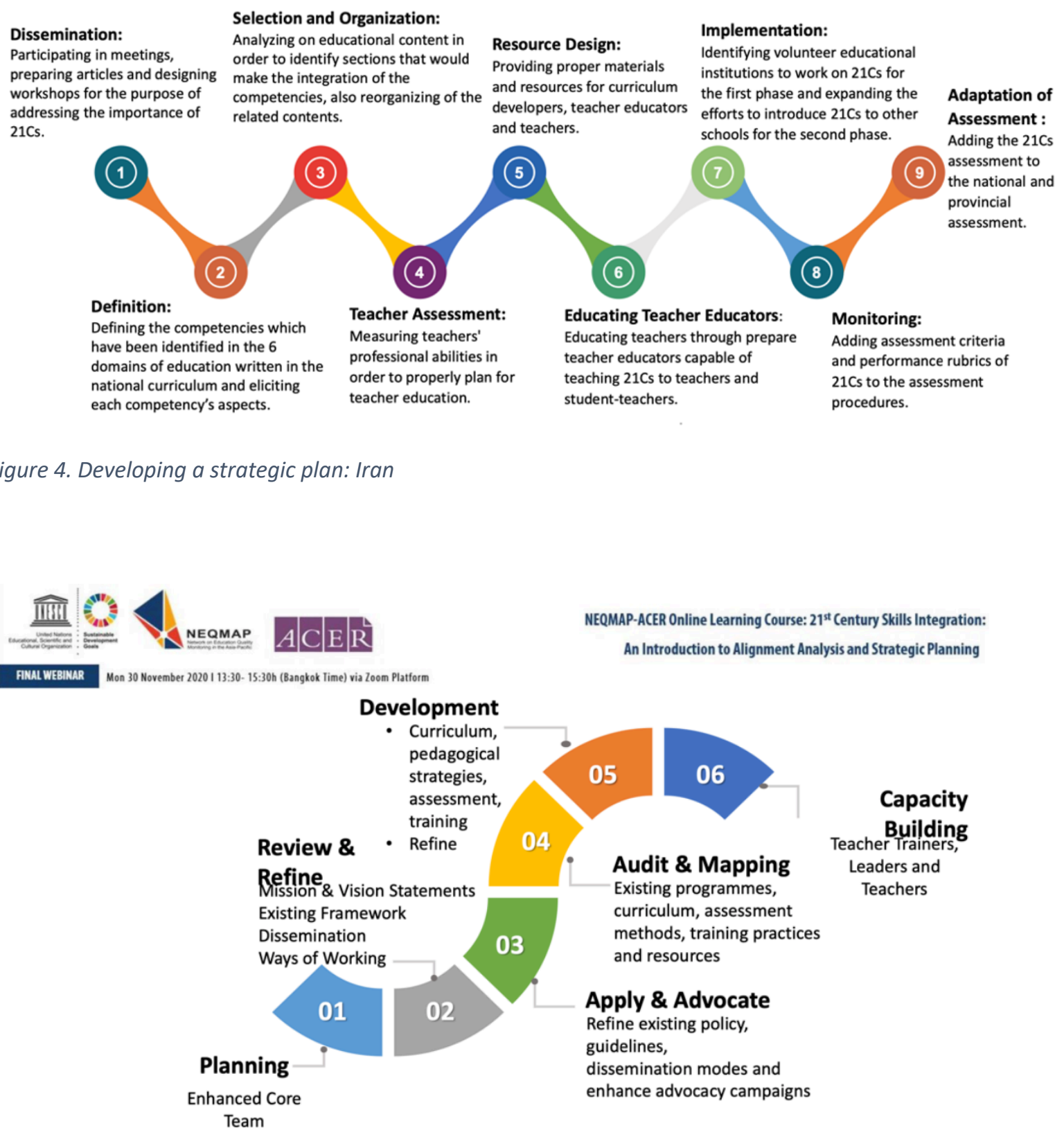

Figure 5. Developing a strategic plan: Malaysia

\section{Lessons learned and conclusion}

The aim of the course was to support systems to build an aligned and sustainable approach to 21CS integration. This was achieved via overall objectives that focused on supporting countries to develop a strategic plan for 21CS integration, providing resources to aid that plan, and building capacity to implement the plan.

One of the objectives of the course was to understand the components and steps to 21CS alignment so that participants could conduct a needs analysis, identifying which steps are currently being met, 
and which steps need more attention. While detailed skill development frameworks were highly valued, these resources were lacking across most countries. More work is therefore required to expand the suite of frameworks, ensure they are appropriately contextualised within countries, and map such frameworks to curriculum-based learning outcomes. Most countries need a lot more support in understanding, identifying and monitoring growth in these skills. The LPs in the ACER frameworks can serve as an appropriate foundational resource to build understanding and capacity in both learners and teachers.

Another main objective of the course was to develop a strategic plan, identifying which steps are to be prioritized and in which order. All countries managed to develop and present a strategic plan upon course conclusion. Different countries prioritized different approaches to integration. Some prioritized curriculum, some assessment. Typically, the last steps across countries were to develop teaching resources and review pedagogical training, which is consistent with other global trends relating to $21 \mathrm{CS}$.

Another objective of the course was to gain insights from other education systems from reflections on successful developments and lessons learned. There were both commonalities and differences between systems that prompted discussion between countries. In their vision and mission statements, most countries tried to strike a balance between developing citizens who would maintain national values and cultural pride while having global outlooks. Countries generally prioritized a common set of skills despite addressing a variety of frameworks and skills during their presentations. Not all skills are valued across all subjects, some are more amenable than others. This appears to be very country-specific depending on the priorities, layout, and needs of the curriculum.

Considering the remote working, blended learning, and team dynamic contexts of this course, the participants remained engaged and interactive throughout, both with facilitators and across systems.

Several countries have also requested follow up courses or more detailed training as a result. In particular, requests for additional support tended to relate to the:

- Implementation of their strategic plan;

- Development of additional skill frameworks with detailed definitions;

- Training for teachers and other stakeholders; and

- Research into best practices for pedagogical strategies to enhance the skills.

This information is very valuable in gaining insight into countries' specific needs around 21CS integration and provides an opportunity to strategically plan future engagement. 